\title{
Growth and body composition in preterm infants with bronchopulmonary dysplasia
}

\author{
W A Huysman, M de Ridder, N C de Bruin, G van Helmond, N Terpstra, \\ J B Van Goudoever, P J J Sauer
}

Arch Dis Child Fetal Neonatal Ed 2003;88:F46-F51

See end of article for authors' affiliations

Correspondence to: Dr Huysman, Sophia Children's Hospital/ Erasmus Medical Center Rotterdam, PO Box 2060 3000 CB Rotterdam, The Netherlands; huysman@alkg.azr.nl

Accepted 16 July 2002

\begin{abstract}
Objective: To compare growth and body composition in preterm infants with bronchopulmonary dysplasia (BPD) with normal healthy term infants during the first year of life.

Design: Twenty nine preterm infants with BPD (mean (SD) gestational age 27.1 (1.6) weeks; birth weight $852(173) \mathrm{g}$ ) were followed prospectively. Anthropometry and body composition determined by total body electrical conductivity were measured and compared with those of healthy term infants at the same post-term age.

Results: In infants with BPD, the mean weight standard deviation scores (SD scores) 6 weeks after term were significantly lower $(-1.44$ and -2.68 , boys and girls respectively) than in healthy term infants of the same age and did not improve during the first year. The mean length SD score was significantly lower in infants with BPD 6 weeks after term than in healthy term infants of the same age, and, although it improved significantly during the first year, the mean length SD score in girls with BPD was significantly below 012 months after term. In infants with BPD, the mean free fat mass (FFM) SD score and the mean total body fat (TBF) SD score at 6 weeks post-term age were significantly below 0 . The mean FFM SD scores $(-1.01$ and -2.56 , boys and girls respectively) and the mean TBF SD scores $(-1.14$ and -2.40 , boys and girls respectively) 12 months after term were significantly lower than in healthy term infants of the same age.

Conclusions: Preterm infants with BPD have impaired growth, with a deficit in TBF and FFM already 6 weeks after term; FFM and TBF remain low compared with healthy term infants during the first year of life. Nutritional intervention studies in infants with BPD are needed to evaluate if nutrition is the major determinant of growth and body composition or if this pattern of growth in preterm infants with BPD is the result of disturbed endocrine control.
\end{abstract}

$\mathrm{P}$ reterm infants who develop bronchopulmonary dysplasia (BPD) show impaired growth during early infancy compared with term ${ }^{12}$ and preterm ${ }^{3}$ infants who do not. The impaired growth sometimes extends over the first few years of life. ${ }^{4}$ Different explanations for the slow growth in infants with BPD have been proposed, such as the increased work required to breathe, early use of corticosteroids, intrauterine growth retardation, early postnatal growth retardation, ${ }^{56}$ and feeding problems related to inadequate intake or high metabolic rate.

In rats, early postnatal starvation results in reduced growth in infancy. ${ }^{8}$ Barker et $\mathrm{al}^{9}{ }^{10}$ showed that intrauterine malnutrition is associated with adult morbidity, especially when the malnutrition is combined with accelerated catch up growth during childhood. ${ }^{11}$ Therefore, both undernutrition and overnutrition during early postnatal life should be avoided. Nutritional intervention should aim to obtain not only an increase in weight and length, but also a body composition comparable to that of healthy term infants.

Body composition can be measured by total body electric conductivity (TOBEC), which has emerged as an accurate, precise, and reproducible method for estimating fat free mass (FFM) and total body fat (TBF). ${ }^{12-14}$ Reference standards for healthy term caucasian Dutch infants for TBF and FFM have been developed by De Bruin et al, ${ }_{1}^{15}$ as well as the normal pattern of TBF and FFM accretion in infants in the first year of life.

No data exist on the pattern of body composition in preterm infants with BPD during the first year of life, and without these data it is impossible to design an appropriate nutritional intervention for infants with BPD and to know whether to recommend supplemental energy or protein or both.
Therefore, the aim of our study was to collect data on growth and body composition in preterm infants with BPD, after discharge from the neonatal intensive care unit, and to compare them with reference data in healthy term infants.

\section{SUBJECTS AND METHODS \\ Subjects}

Patients were enrolled in the study between January 1997 and January 1999, had a gestational age $\leqslant 30$ weeks, and had developed BPD according to the criteria of Northway et al. ${ }^{16}$ All patients had been admitted to the neonatal intensive care unit of Sophia Children's Hospital. The study was approved by the local medical ethics committee, and informed consent was obtained from the parents of each child.

All patients were prospectively followed at the neonatal follow up clinic at the post-term ages of 6 weeks, 3, 6, 9, and 12 months. During these follow up visits, recumbent crown-heel length, weight, and head circumference were measured. TOBEC measurements were only performed if the infants weighed more than $3 \mathrm{~kg}$, because such measurements are only validated for infants with a body weight of $3-10 \mathrm{~kg} .{ }^{13}$ Neonatal risk factors such as intrauterine growth retardation, use of antenatal steroids, duration of ventilation, duration of supplemental oxygen, use of dexamethasone, sepsis, necrotising enterocolitis, and intraventricular haemorrhage were determined. None of the infants showed signs of fluid retention or was artificially ventilated during the period of study.

Abbreviations: BPD, bronchopulmonary dysplasia; TOBEC, total body electric conductivity; FFM, fat free mass; TBF, total body fat 
Table 1 Neonatal data for 29 infants with bronchopulmonary dysplasia

\begin{tabular}{llll}
\hline & Mean & SD & No \\
\hline Gestational age (weeks) & 27.1 & 1.6 & \\
Birth weight (g) & 852 & 173 & \\
Birth weight SD score & -1.11 & 1.17 & \\
Head circumference & -0.21 & 1.10 & \\
Apgar 1 min & 5.0 & 2.5 & \\
Apgar 5 min & 7.8 & 1.7 & \\
Dexamethasone treatment (days) & 32.5 & 34.9 & \\
Ventilation (days) & 29.1 & 15.8 & \\
Extra O ${ }_{2}$ requirement (days) & 201 & 221 & \\
Antenatal steroids & & & 25 \\
HELLP & & & 12 \\
PROM & & & 23 \\
RDS treated with surfactant & & & 22 \\
Ductus treated with indocid and/or ligation & & & 19 \\
Sepsis & & & 6 \\
Intraventricular haemorrhage > grade 2 & &
\end{tabular}

HELLP, haemolysis elevated liver enzymes-low platelet syndrome; PROM, premature rupture of the membranes; RDS respiratory distress syndrome.

Table 2 Daily nutritional intake in preterm infants with bronchopulmonary dysplasia during the first half year of life

\begin{tabular}{lccc}
\hline & 6 weeks & 3 months & 6 months \\
\hline $\begin{array}{l}\text { Volume intake } \\
\text { (ml/kg/day) }\end{array}$ & $138(28)$ & $142(30)$ & $115(17)$ \\
$\begin{array}{l}\text { Energy intake } \\
\text { (kcal/kg/day) }\end{array}$ & $119(32)$ & $109(26)$ & $100(21)$ \\
$\begin{array}{l}\text { Protein intake } \\
\text { (g/kg/day) }\end{array}$ & $2.7(0.7)$ & $2.4(0.5)$ & $2.2(0.4)$ \\
Fat intake (g/kg/day) & $6.7(2.5)$ & $5.7(1.5)$ & $4.1(1.0)$ \\
\hline
\end{tabular}

Values are mean (SD) at given post-term age.

We calculated dietary intake by recording a 48 hour feeding history during each visit at the neonatal follow up clinic. All infants received formula feeding according to the policy on the unit, and were exclusively formula fed until at least 3 months post-term age. Solid food was introduced at a time determined by the paediatrician (current Dutch recommendations for term infants are to introduce solids at 4-6 months of age).

\section{Anthropometric measurements}

Anthropometric measurements were carried out by one observer $(\mathrm{MH})$ at each visit. Recumbent crown-heel length was measured to the nearest millimetre on a length board. Weight was measured on an electronic baby scale (TEC, Tokyo Electronic Co, Tokyo, Japan) to the nearest gram. Head circumference (fronto-occipital) was measured using a standard plastic measuring tape ( $1 \mathrm{~cm}$ wide) to the nearest millimetre. All anthropometric measurements were performed three times, and the mean was used for analysis. Birth weight was expressed as SD scores for gestational age according to the standards of Usher and McLean. ${ }^{17}$ The anthropometric measurements after discharge were expressed as SD scores for post-term age, according to the Dutch reference. ${ }^{18}$

\section{Measurement of body composition}

The TOBEC measurements (Body Composition Analyser, model HP-2; EM-Scan Inc, Springfield, Illinois, USA) were performed by $\mathrm{GH}$ and $\mathrm{MH}$. The principle underlying the TOBEC technique is that lean tissue or FFM is far more electrically conductive than fat, because of its greater content of electrolytes. When a conductive mass passes through the electromagnetic field, a small amount of energy is produced

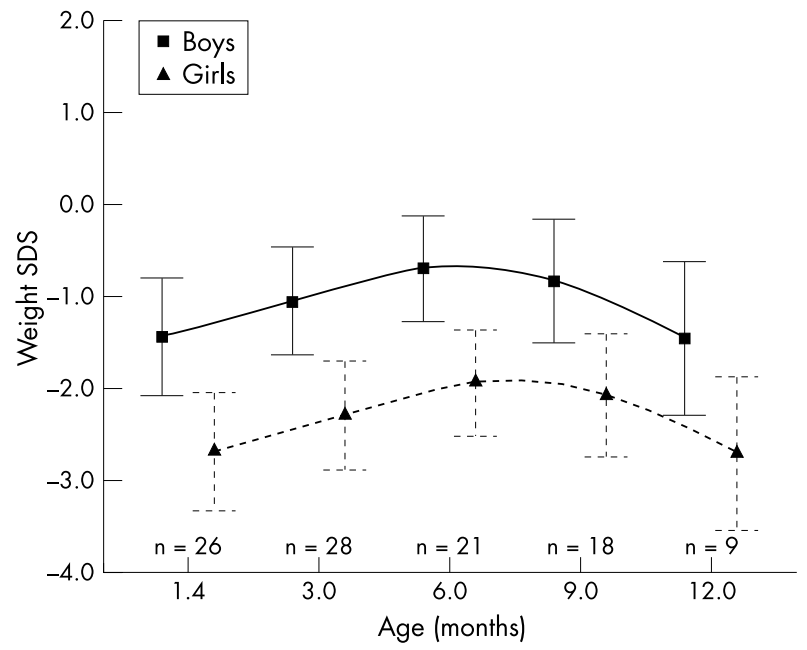

Figure 1 Weight SD scores (SDS) in infants with bronchopulmonary dysplasia plotted against post-term age in the first year of life. The mean and the 25th and 75 th centiles are shown.

within the conductive mass. This energy is distracted from the magnetic field, detected as a phase change in coil impedance, and serves as an index of the amount of conductive mass-that is, the infant's FFM. The amount of TBF is calculated by subtracting FFM from body weight.

The TOBEC procedure was carried out as described by De Bruin et al ${ }^{14}$ Before each measurement, background noise and a cylindrical reference phantom were measured. All measurements were performed in the peak mode. The infants were undressed and carefully swaddled in a fully extended position in a large blanket. Care was taken that the limbs did not touch each other or the trunk. The infants were not fed for two hours before the measurement and they did not have a fever. When the infant had urinated, it was swaddled again in a dry blanket and measured again.

One TOBEC reading took about 10 seconds, and a complete TOBEC measurement consisted of 8-10 of these readings. The mean of the readings was taken for further body composition calculations. FFM, TBF, and TBF as a percentage of weight (\%TBF) were calculated. The SD scores for FFM, TBF, and \%TBF were expressed for post-term age using the reference centiles for body composition constructed by De Bruin et al. ${ }^{15}$ Hydration is known to influence the conductance of the FFM, and is a potential measurement error in non-stable infants. As all our infants were stable with supplemental oxygen without a need for additional diuretic treatment, we believe that the calculation of the FFM was not influenced by their hydration.

\section{Statistical analysis}

Statistical analysis was performed using SPSS 9.0 for Windows 95 (SPSS Software, Chicago, Illinois, USA) and SAS version 8.0 for Windows (SAS Institute Inc, Cary, North Carolina, USA). Differences in baseline data between boys and girls were tested with Student's $t$ test. All statistical analysis requiring repeated measurement analyses were carried out using SAS Proc mixed. Repeated measurement analyses were performed because of incomplete data for some of the infants. We used a model for repeated measurements with a random intercept and a random slope (age) for the subjects. The models for anthropometric data included age and sex as fixed effects, and the interaction between age and sex if significant. The models for body composition data also included weight, to correct for the fact that infants weighing less than $3 \mathrm{~kg}$ could not be measured by TOBEC. Using these models, we tested the differences in absolute values between boys and girls with $\mathrm{BPD}$, the differences between infants with BPD and the reference population by measuring the difference from zero for the 
Table 3 Anthropometric measurements in preterm infants with bronchopulmonary dysplasia during the first year of life

\begin{tabular}{llllll}
\hline & 6 weeks & 3 months & 6 months & 9 months & 12 months \\
\hline Boys & & & & & \\
Weight $(\mathrm{kg})$ & $3.863(0.128)$ & $5.156(0.127)$ & $7.038(0.178)$ & $8.209(0.259)$ & $8.670(0.364)$ \\
Length $(\mathrm{cm})$ & $51.4(0.6)$ & $56.7(0.6)$ & $64.8(0.6)$ & $70.5(0.7)$ & $73.9(0.9)$ \\
Head circumference $(\mathrm{cm})$ & $37.9(0.3)$ & $40.2(0.3)$ & $43.5(0.3)$ & $45.4(0.4)$ & $46.0(0.4)$ \\
Girls & $3.134(0.134)$ & $4.276(0.132)$ & $5.874(0.176)$ & $6.761(0.246)$ & $6.938(0.337)$ \\
Weight $(\mathrm{kg})$ & $48.8(0.6)$ & $54.1(0.6)$ & $62.3(0.7)$ & $67.9(0.7)$ & $71.3(0.9)$ \\
Length $(\mathrm{cm})$ & $36.0(0.4)$ & $38.3(0.4)$ & $41.6(0.4)$ & $43.5(0.4)$ & $44.1(0.4)$ \\
Head circumference $(\mathrm{cm})$ & \\
\hline
\end{tabular}

mean SD scores, and we measured the differences in mean SD scores at different ages in the infants with BPD.

To compare data at different ages, the means given in the Results section were calculated (estimated) means from the repeated measurement models. $p<0.05$ was considered significant. Pearson correlation was used to evaluate the relation between nutritional intake and growth.

\section{RESULTS}

Twenty nine patients with BPD ( 15 boys) were prospectively followed up. Table 1 shows the baseline characteristics and neonatal morbidity of these infants. The mean (SD) gestational age was 27.1 (1.6) weeks. The boys with BPD had a significantly higher mean birth weight 955 (165) g and mean birth weight SD score -0.56 (1.0) than the girls with BPD (743 (102) g and -1.69 (1.0) respectively; $p<0.001$ and $\mathrm{p}<0.01$ respectively). The mean head circumference SD score in the boys was significantly higher than in the girls $(p<0.01)$. The boys and girls with BPD were not significantly different with regard to their perinatal morbidity, particularly the number of days receiving dexamethasone, artificial ventilation, or supplemental oxygen. All infants developed BPD as defined by Northway et $a l^{16}$ and 21 infants progressed to chronic lung disease, defined as a requirement for supplemental oxygen at 36 weeks postconceptional age. Twenty six infants were treated with dexamethasone in order to be weaned from the ventilator. Feeding history could be accurately collected until 6 months post-term age. Weaning was started at 3 months post-term age in some of the infants, but most were predominantly formula fed until 6 months post-term age. Table 2 shows the calculated energy, protein, and fat intake during the first half year after term.

\section{Anthropometric measurements}

Table 3 gives the mean weight, length, and head circumference during the first year of life. As in healthy infants, a clear sex difference was seen. The boys with BPD had a significantly higher mean weight, length, and head circumference at all ages than the girls with BPD $(\mathrm{p}<0.001)$.

In boys and girls with BPD, a similar growth pattern for weight and length was seen. Infants with BPD had significantly lower mean weight SD scores at 6 weeks postterm age than healthy term infants of the same age $(-1.44$ and -2.68 , boys and girls respectively; $p<0.0001)$. The mean weight SD score improved significantly from 6 weeks to 6 months post-term age ( $p<0.0001)$, but worsened again from 6 months to 12 months post-term age $(p<0.0001)$. At 12 months after term, the mean weight SD score in infants with BPD was not significantly improved compared with the mean weight SD score at 6 weeks after term and remained significantly lower than in healthy term infants of the same age $(\mathrm{p}<0.0001)$ (fig l).

Infants with BPD had significantly lower mean length SD scores at 6 weeks post-term age than healthy infants of the

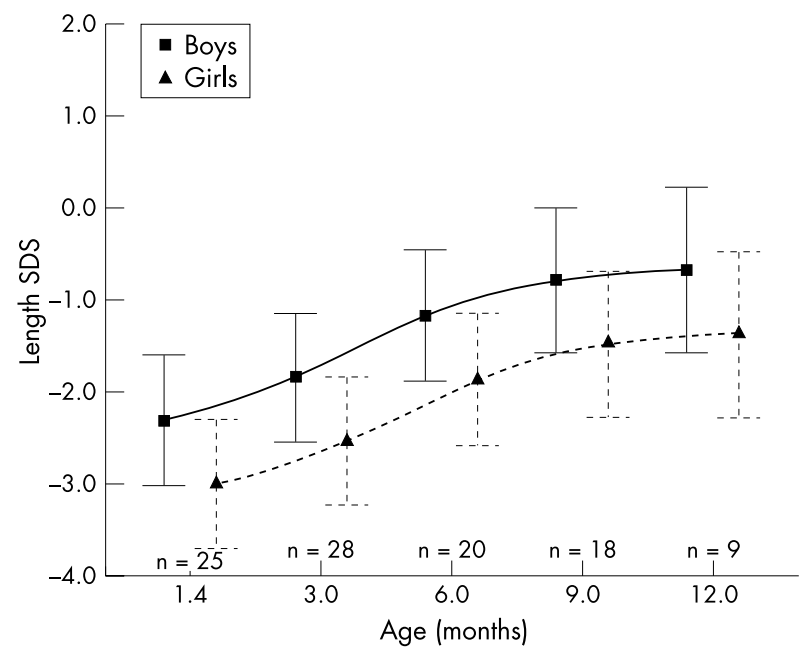

Figure 2 Length SD scores (SDS) in infants with bronchopulmonary dysplasia plotted against post-term age in the first year of life. The mean and the 25 th and 75 th centiles are shown.

same age $(-2.31$ and -2.99 , boys and girls respectively; $\mathrm{p}<0.0001)$. The mean length SD scores improved significantly from 6 weeks to 12 months post-term age ( $p<0.0001$ ). In girls with $\mathrm{BPD}$, the mean length SD score was significantly lower than in healthy term infants at 12 months post-term age $(\mathrm{p}<0.001)$ ( fig 2$)$.

\section{Measurements of body composition}

Total FFM increased gradually during the first year of life in infants with BPD (table 4). TBF increased during the first 9 months after term, but decreased between 9 and 12 months after term.

FFM and TBF in the infants with BPD were compared with sex specific body composition data for healthy term Dutch infants of the same post-term age and expressed in SD scores (fig 3). Although variability is seen between patients, the pattern for each individual patient is quite constant. In infants with BPD, the mean FFM SD scores were significantly below 0 at 6 weeks post-term age $(-2.39$ and -3.11 , boys and girls respectively; $\mathrm{p}<0.0001$ ). They increased slightly during the first year, but were significantly lower than in healthy term infants at 12 months post-term age $(-1.01$ and -2.56 , boys and girls respectively; $\mathrm{p}<0.001$ ).

The mean TBF SD scores in infants with BPD were significantly below 0 at 6 weeks post-term age $(-0.91$ and -0.73 for boys and girls respectively; $\mathrm{p}<0.05)$. The mean TBF SD scores at 12 months post-term age were significantly lower than in healthy infants of the same age $(-1.14$ and -2.40 , boys and girls respectively; $\mathrm{p}<0.005$ ).

The mean \%TBF SD score in infants with BPD was not significantly below 0 at 6 weeks post-term age. However, at 12 
Table 4 Body composition in preterm infants with bronchopulmonary dysplasia during the first year of life

\begin{tabular}{|c|c|c|c|c|c|}
\hline & 6 weeks & 3 months & 6 months & 9 months & 12 months \\
\hline \multicolumn{6}{|l|}{ Boys } \\
\hline FFM (kg) & $3.300(0.070)^{* * *}$ & $4.127(0.069)^{* * *}$ & $5.393(0.078)^{* * *}$ & $6.297(0.089)^{* * *}$ & $6.838(0.105)^{* * *}$ \\
\hline TBF $(\mathrm{kg})$ & $0.560(0.070)$ & $1.033(0.069)$ & $1.647(0.078)^{* *}$ & $1.913(0.089)^{* * * *}$ & $1.831(0.105)^{* * *}$ \\
\hline$\% \mathrm{TBF}$ & $15.3(1.6)$ & $19.0(1.5)$ & $23.2(1.5)$ & $24.0(1.6)$ & $21.3(1.7)$ \\
\hline \multicolumn{6}{|l|}{ Girls } \\
\hline FFM $(\mathrm{kg})$ & $2.637(0.078)$ & $3.387(0.076)$ & $4.506(0.079)$ & $5.266(0.089)$ & $5.665(0.110)$ \\
\hline TBF $(\mathrm{kg})$ & $0.493(0.078)$ & $0.893(0.075)$ & $1.364(0.079)$ & $1.493(0.089)$ & $1.274(0.110)$ \\
\hline$\% \mathrm{TBF}$ & $17.0(1.7)$ & $20.0(1.6)$ & $22.8(1.5)$ & $22.2(1.5)$ & $18.2(1.7)$ \\
\hline
\end{tabular}

Results are expressed as estimated mean (SE) at given post-term ages.

${ }^{* *} p<0.01,{ }^{* *} p<0.001$, significantly different from girls with BPD.

FFM, fat free mass; TBF, total body fat; \%TBF, percentage TBF.

months post-term age, the mean \%TBF in girls with BPD was -2.05 and significantly lower than in healthy term infants of the same age $(\mathrm{p}<0.0001)$.

\section{Nutritional intake}

The relation between nutritional intake at the start of a period (from 6 weeks to 3 months, from 3 to 6 months, and from 6 to 9 months post-term age) and the increase in absolute weight, length, FFM, and TBF at the end of that period was evaluated. No correlation was found between the energy and protein intake at 6 weeks, 3 and 6 months post-term age and the absolute gain in weight, length, FFM, and TBF.

The relation between nutritional intake at the start of a period and the change in SD score during that period was evaluated. No correlation was found between energy and protein intake at 6 weeks, 3 and 6 months post-term age and the change in SD score for weight, length, FFM, and TBF.

\section{DISCUSSION}

This study was designed primarily to measure the length, weight, and body composition of preterm infants with BPD during their first year of life and to compare these with data obtained for healthy term infants.

The first result of interest is that weight, length, FFM, and TBF in infants with BPD were already low at the first measurement at 6 weeks post-term age, indicating that the growth pattern was already abnormal in early life and that a deficit in FFM and TBF had built up in the first months of life. Interestingly, both FFM and TBF were low, resulting in a proportionately normal body composition.

Several other studies already showed early postnatal growth retardation in preterm infants especially in those with major morbidities such as BPD. ${ }^{56}$ We report for the first time that this growth retardation has an effect on both TBF and FFM. Prenatal growth retardation has a similar effect on body composition, resulting in lower FFM and TBF. ${ }^{19}$

The second result of interest is that growth during the first year in infants with BPD was not sufficient to catch up. Infants with BPD have a significantly lower weight, length, FFM, and TBF than healthy term infants at 12 months post-term age. This was despite the fact that the energy and protein intake during the first six months after term were at, or even above, the recommendations for healthy term infants. ${ }^{2021}$

There are several possible explanations for the reduced growth in preterm infants with BPD. In the early neonatal period, major morbidities resulting in a delay in starting and achieving full enteral feeding may be a major cause. ${ }^{6}$ Subsequently, when enteral feeding is established, difficulties in sucking and swallowing or gastro-oesophageal reflux ${ }^{22-24}$ may lead to a lower intake of energy and protein than calculated. Furthermore, frequent pulmonary infections may lead to episodes of decreased intake with consequently lower growth rates. It has also been argued that the energy and protein requirements of infants with BPD are higher because of an elevated resting metabolic rate, caused by a high respiratory rate due to lower lung compliance. ${ }^{23} 2526$ Recurrent episodes of hypoxaemia during feeding and sleep may result in inadequate oxygenation for metabolic demands, with subsequent insufficient use of dietary substrates. ${ }^{27}{ }^{28}$ However, we can extract from our data that the nutritional intake of the preterm infants with BPD in this study was insufficient to achieve catch up growth. This may indicate that preterm infants with BPD need a higher intake of energy and protein after discharge than recommended for healthy term infants. Another possible explanation is that the growth disturbance in the perinatal period resulted in disturbance of the endocrine control of growth with long term effects on the growth pattern.

It is important to emphasise three aspects of the study. Firstly, the number of subjects is relatively small because we decided to include cases encountered over a period of two years only. We did not want to prolong the inclusion period, because the changes in medical and nutritional treatments that are likely to occur over a long period may have influenced the outcome. Secondly, the food intake of the infants was not controlled, so as to collect growth and body composition data in the situation present in most paediatric departments. Thirdly, we were only able to compare our patients with healthy term infants and not with a healthy preterm control group. The results obtained can be explained by the presence of BPD in these preterm infants, but may also be explained by prematurity itself.

TOBEC is a reliable and validated method for measuring body composition. We were therefore able to compare the data in preterm infants with BPD with data from healthy term Dutch infants. At the end of the first year, TBF and FFM in these preterm infants with BPD was still low compared with that in controls. ${ }^{15}$ Also, when compared with the reference infants described by Fomon et al, ${ }^{29}$ the infants with BPD have lower FFM and TBF at the end of the first year.

Other data on body composition in (pre) term infants during the first year of life have recently been published. Butte et $a l^{30}$ combining several techniques to measure body composition, showed that FFM was slightly higher in healthy term infants and TBF was much higher than in our children with BPD. Rawlings et $a l^{31}$ found a similar pattern of accretion of FFM and TBF in preterm infants to that in our study, with an increase in FFM during the first year, while TBF increased from birth till 6 months, but not between 6 and 12 months. Both in the study of Rawlings et al and in our study, FFM was significantly lower than the reference data. Interestingly, the absolute amount of TBF was higher in their study, and not different between boys and girls. This may partly be explained by the method used, as Rawlings et al used the dual energy $x$ ray absorptiometry method, which may have overestimated $\mathrm{TBF}$, or it may be due to differences between the groups of infants studied. The number of girls included in our study who were small for gestational age may have influenced our results. 

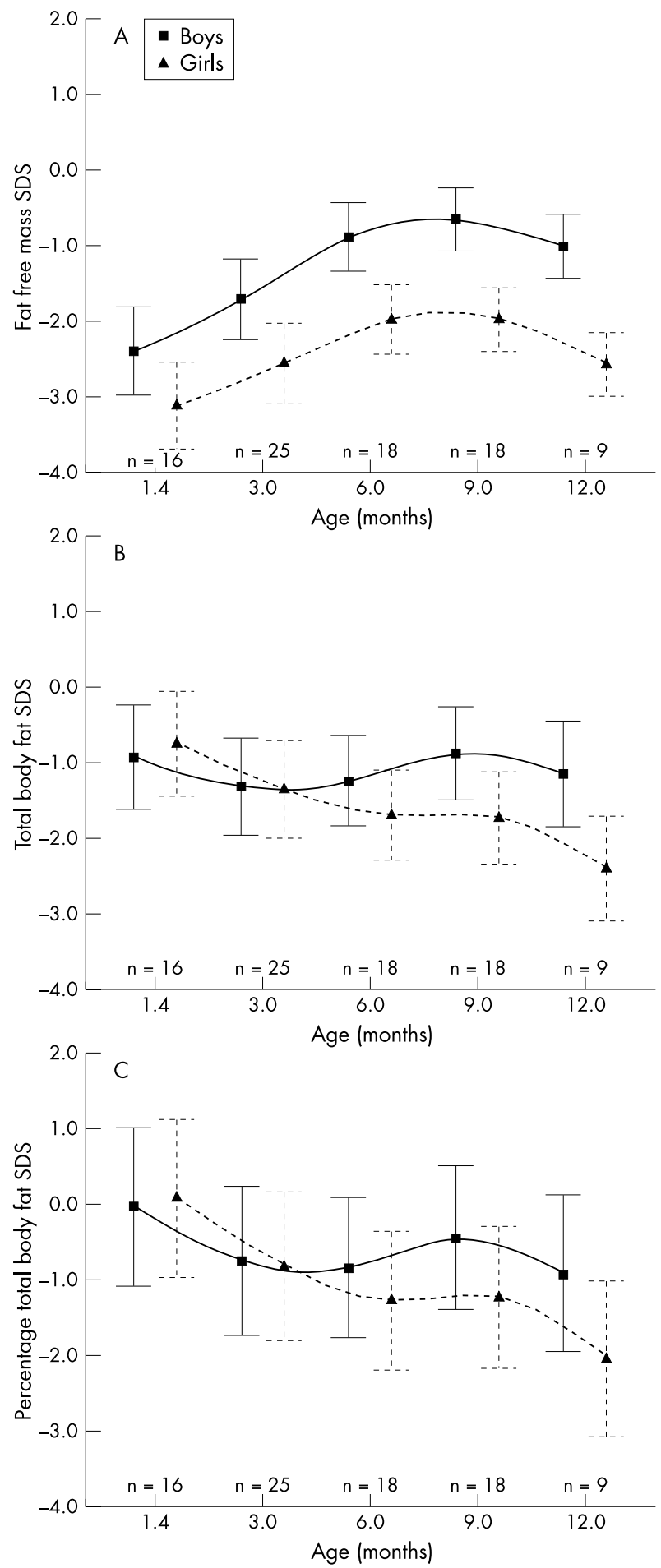

Figure 3 Fat free mass (A), total body fat (B), and \% total body fat (C) in infants with bronchopulmonary dysplasia plotted against post-term age in the first year of life. The mean and the 25 th and 75th centiles are shown.

The fact that FFM and TBF in our preterm infants with BPD were lower than healthy term reference values, measured by the same method, may have different explanations. It may well be that BPD itself causes less deposition of FFM and TBF because of inadequate absorption of nutrients during the acute phase of lung disease, the medical treatment of the infants (with fluid restriction, steroids, and diuretics), elevated metabolic rate, and the increased work of breathing. The data of Rawlings et $a^{31}$ suggest that prematurity itself may also explain at least some of our results. As we did not have a control group of healthy preterm infants, it is not possible to conclude whether the effect on FFM and TBF is due to BPD or prematurity itself. Finally, growth retardation at birth or during the first few weeks of life in preterm infants, especially those with major morbidities as observed by Ehrenkranz et $a l,{ }^{6}$ may have caused a persisting abnormal body composition.

Dietary manipulation of growth rates and body composition in preterm infants seems reasonable. ${ }^{32-37}$ Increases in weight, TBF, and FFM have been obtained in preterm boys, but not girls, who were fed a preterm formula (higher in energy, protein, calcium, and phosphorus) from discharge for 6 months. The authors attributed the changes in growth and body composition to the higher protein intake. ${ }^{34}$ Recent intervention studies have shown a positive effect on weight, length, and head circumference, especially in boys. ${ }^{36-38}$ So far, only one study, by Brunton et al, ${ }^{32}$ has described the effect of nutritional intervention in infants with BPD. Feeding an enriched formula ( $2.5 \mathrm{~g}$ protein $/ \mathrm{kg} /$ day compared with $2.0 \mathrm{~g}$ protein $/ \mathrm{kg} /$ day) resulted in a significantly greater gain in length and FFM, but not in weight, in infants with BPD fed the enriched formula at 3 months of age. From this study, it seems to be possible to increase FFM and linear growth by giving a high protein/high mineral formula. Interestingly, the intake for our infants was comparable to the enriched formula, but both weight and FFM were lower in our children than in the infants studied by Brunton et al.

Interpretation of body composition data depends on whether post-term age or body weight is regarded as the appropriate reference. The weights of our preterm infants with BPD at 6 weeks post-term age are comparable to the weights of healthy newborn infants, and the \% TBF is comparable to the \%TBF found by TOBEC and dual energy $x$ ray absorptiometry in healthy term neonates. ${ }^{39-41}$ Also, the FFM in infants with BPD is comparable to that of infants of equal weight.

These data, together with the anthropometric data, indicate that preterm infants with BPD are growth retarded, with less body fat and lean mass than healthy infants of the same postterm age, and they have body proportions regarding fat free mass and fat according to their weight. As this growth restriction may have permanent effects, interventions are needed to improve growth in these preterm infants. Long lasting nutritional intervention studies with both increased protein and energy are needed to determine whether this will improve growth and body composition at a later age. As growth disturbance in the perinatal period may result in disturbance of the endocrine control of growth, these studies should include hormonal evaluations. Measurements of body composition are essential in these studies to evaluate the FFM and TBF and to prevent overnutrition in some infants.

\section{Authors' affiliations}

W A Huysman, G van Helmond, N Terpstra, J B Van Goudoever, Department of Pediatrics, Division of Neonatology, Sophia Children's Hospital, Rotterdam, The Netherlands

$M$ de Ridder, Department of Biostatistics and Epidemiology, Erasmus University, 3000 DR Rotterdam

N C de Bruin, Verpleeghuis Drie Maashaven, 3146 CT Maassluis, The Netherlands

P J J Saver, Department of Pediatrics, Beatrix Children's Hospital/ University Hospital Groningen, 9700 CB Groningen, The Netherlands

\section{REFERENCES}

1 Davidson S, Schrayer A, Wielunsky E, et al. Energy intake, growth, and development in ventilated very-low-birth-weight infants with and without bronchopulmonary dysplasia. American Journal of Diseases in Children 1990;144:553-9.

2 Markestad T, Fitzhardinge PM. Growth and development in children recovering from bronchopulmonary dysplasia. J Pediatr 1981;98:597-602.

3 Vohr BR, Bell EF, Oh W. Infants with bronchopulmonary dysplasia: growth pattern and neurologic and developmental outcome.American Journal of Diseases in Children 1982;136:443-7. 
4 Robertson ChMT, Etches PhCh, Goldson E, et al. Eight-year school performance, neurodevelopmental, and growth outcome of neonates with bronchopulmonary dysplasia: a comparative study. Pediatrics 1992;89:365-72.

5 DeRegnier RO, Guilbert ThW, Mills MM et al. Growth failure and altered body composition are established by one month of age in infants with bronchopulmonary dysplasia. J Nutr 1996;126:168-75.

6 Ehrenkranz SA, Younes N, Lemons JA, et al. Longitudinal growth of hospitalized very low birth weight infants. Pediatrics 1999; 104:280-9.

7 Yeh TF, McClenan DA, Ajayi OA, et al. Metabolic rate and energy balance in infants with bronchopulmonary dysplasia. J Pediatr $1989 ; 114: 448-51$

8 Widdowson EM, McCance RA. The effect of finite periods of undernutrition at different ages on the composition and subsequent development of the rat. Proc R Soc Lond Biol Sci 1963;152:329-42.

9 Barker DJP, Osmond C, Winter PD, et al. Weight in infancy and death from ischaemic heart disease. Lancet 1989;ii:577-80.

10 Osmond C, Barker DJP, Winter PD, et al. Early growth and death from cardiovascular disease in women. BM 1993;307:1519-24.

11 Eriksson JG, Forsen T, Tuomilehto J, et al. Catch-up growth in childhood and death from coronary heart disease: longitudinal study. BM 1999;318:427-31

12 Fiorotto ML, De Bruin NC, Brans YW, et al. Total body electrical conductivity measurements: an evaluation of current instrumentation for infants. Pediatr Res 1995:37:94-100.

13 De Bruin NC, Westerterp KR, Degenhart HJ, et al. Measurement of fat free mass in infants. Pediatr Res 1995;38:411-17.

14 De Bruin NC, Van Velthoven KAM, Stijnen T, et al. Quantitative assessment of infant body fat by anthropometry and total-body electrical conductivity. Am J Clin Nutr 1995:61:279-86.

15 De Bruin NC, Van Velthoven CAM, Stiinen T, et al. Standards for infant body fat and fat-free mass. Arch Dis Child 1996;74:386-99.

16 Northway WH, Rosan RC, Porter DY. Pulmonary disease following respiratory therapy of hyaline membrane disease: bronchopulmonary dysplasia. N Engl J Med 1967:276:357-68.

17 Usher R, Mclean F. Intrauterine growth of liveborn caucasian infants at sea level: standard obtained from measurements of infants born between 25 and 44 weeks of gestation. J Pediatr 1969;74:901-10.

18 Roede MJ, Van Wieringen JC. Growth diagrams 1980, Netherlands. Third nation-wide survey. Tiidschrift Sociale Gezondheidszorg 1985;63(suppl): 1-34

19 Lapillone A, Braillon P, Claris O, et al. Body composition in appropriate and in small for gestational age infants. Acta Paediatr 1997:86:196-200.

20 Denne SC. Protein requirements. In: Polin RA and Folix WW, eds. Fetal and neonatal physiology. 2nd ed. New York: WB Saunders, 1998:315-24

21 Denne SC. Energy requirements. In: Polin RA and Folix WW, eds. Fetal and neonatal physiology. 2nd ed. New York: WB Saunders, 1998:307-14.

22 Perlman JM, Volpe JJ. Movement disorder of premature infants with severe bronchopulmonary dysplasia: a new syndrome. Pediatrics 1989;84:215-18.
23 Kurzner SI, Garg M, Bautista DB, et al. Growth failure in infants with bronchopulmonary dysplasia: nutrition and elevated resting metabolic expenditure. Pediatrics 1988;81:379-84.

24 Sindel BD, Maisels J, Ballantine TVN. Gastrooesophageal reflux to the proximal esophagus in infants with bronchopulmonary dysplasia. American Journal of Diseases in Children 1989;143:1 103-6.

25 Weinstein MR, Oh W. Oxygen consumption in infants with bronchopulmonary dysplasia. J Pediatr 1981;99:958-61.

26 De Meer K, Westerterp KR, Houwen RHJ, et al. Total energy expenditure in infants with bronchopulmonary dysplasia is associated with respiratory status. Eur J Pediatr 1997;156:299-304.

27 Singer L, Martin RJ, Hawkins SW, et al. Oxygen desaturation complicates feeding in infants with bronchopulmonary dysplasia after discharge. Pediatrics 1992;90:380-4.

28 Garg M, Kurzner SI, Bautista DB, et al. Clinically unsuspected hypoxia during sleep and feeding in infants with bronchopulmonary dysplasia. Pediatrics 1988;81:635-42.

29 Fomon SJ, Haschke F, Ziegler EE, et al. Body composition of reference children from birth to age 10 years. Am J Clin Nutr 1982;35:1 169-75.

30 Butte NF, Wong WW, Hopkinson JM, et al. Energy requirements derived from total energy expenditure and energy deposition during the first 2 y of life. Am J Clin Nutr 2000;72:1558-69.

31 Rawlings DJ, Cooke RJ, McCormick K, et al. Body composition of preterm infants during infancy. Arch Dis Child 1999:80:F188-91.

32 Brunton JA, Saigal S, Atkinson SA. Growth and body composition in infants with bronchopulmonary dysplasia up to 3 months corrected age: a randomized trial of a high energy-nutrient-enriched formula fed after hospital discharge. J Pediatr 1998;133:340-5.

33 Lucas A, Bishop NJ, King FJ, et al. Randomised trial of nutrition for preterm infants after discharge. Arch Dis Child 1992;67:324-7.

34 Cooke RJ, McCormick K, Griffin IJ, et al. Feeding preterm infants after hospital discharge: effect of diet on body composition. Pediatr Res 1999;46:461-4.

35 Van Goudoever JB, Sulkers EJ, Lafeber HN, et al. Short-term growth and substrate use in very-low-birth-weight infants fed formulas with different energy contents. Am J Clin Nutr 2000;71:816-21.

36 Carver JD, Wu PYK, Hall RT. Growth of preterm infants fed nutrient-enriched or term formula after hospital discharge. Pediatrics 2001;107:683-9.

37 Lucas A, Fewtrell MS, Morley R. Randomized trial of nutrient-enriched formula versus standard formula for post-discharge preterm infants. Pediatrics 2001; 108:703-11.

38 Cooke RJ, Embleton ND, Griffin IJ, et al. Feeding preterm infants after hospital discharge: growth and development at 18 months of age. Pediatr Res 2001:49:719-22.

39 Fiorotto ML, Cochran WJ, Klish WJ. Fat-free mass and total body water of infants estimated from total body electrical conductivity measurements. Pediatr Res 1987;22:417-21.

40 Venkataraman PS, Ahluwalia BW. Total bone mineral content and body composition by X-ray densitometry in newborns. Pediatrics 1992:90:767-70.

41 Rigo J, Nyamugabo K, Picaud JC, et al. Reference values of body composition obtained by dual energy X-Ray absorptiometry in preterm and term neonates. J Pediatr Gastroenterol Nutr 1998;27: 184-90. 